\title{
Marc Bressant, Les Funérailles de Victor Hugo
}

\section{Valentina Ponzetto}

\section{OpenEdition}

\section{Journals}

\section{Edizione digitale}

URL: http://journals.openedition.org/studifrancesi/3793

DOI: 10.4000/studifrancesi.3793

ISSN: 2421-5856

\section{Editore}

Rosenberg \& Sellier

\section{Edizione cartacea}

Data di pubblicazione: 1 décembre 2012

Paginazione: $589-590$

ISSN: 0039-2944

Notizia bibliografica digitale

Valentina Ponzetto, «Marc Bressant, Les Funérailles de Victor Hugo», Studi Francesi [Online], 168 (LVI

III) | 2012, online dal 30 novembre 2015, consultato il 07 mars 2021. URL: http://

journals.openedition.org/studifrancesi/3793 ; DOI: https://doi.org/10.4000/studifrancesi.3793

Questo documento è stato generato automaticamente il 7 mars 2021.

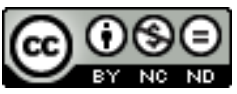

Studi Francesi è distribuita con Licenza Creative Commons Attribuzione - Non commerciale - Non opere derivate 4.0 Internazionale. 


\title{
Marc Bressant, Les Funérailles de Victor Hugo
}

\author{
Valentina Ponzetto
}

\section{NOTIZIA}

MARC BRESSANT, Les Funérailles de Victor Hugo, Paris, Michel de Maule, «Je me souviens», 2011, pp. 83.

1 Il funerale di Victor Hugo fu un lutto nazionale. Un evento pubblico di proporzioni colossali che vide riversarsi per le vie di Parigi il 1 giugno 1885 più di due milioni di persone, forse persino tre, secondo certe fonti, in ogni caso «la plus grande foule jamais rassemblée à Paris». Un momento memorabile, ma anche altamente simbolico: una sorta di battesimo della giovane Terza Repubblica francese e una celebrazione dei suoi valori di laicità e democrazia attraverso l'apoteosi del suo più grande uomo di lettere, condotto in trionfo verso il Pantheon precipitosamente riconvertito per l'occasione alla sua primaria funzione di mausoleo laico per funerali di Stato.

2 Marc Bressant, premiato romanziere, affronta il soggetto con penna da scrittore alla moda, ovvero da un punto di vista personale, memoriale, in bilico fra autobiografia e autofiction. Ora, come parlare in prima persona di un evento del 1885 essendo nati nel 1938 e senza ricorrere all'intermediario di un alter-ego romanzesco, che abolirebbe la ricercata qualità di autenticità e testimonianza di vita vissuta? Grazie all'intermediazione di un personaggio chiave: la nonna dell'autore, bambina di otto anni e nondimeno attento e partecipe testimone oculare all'epoca dei fatti. Le frase pronunciata dalla donna ormai anziana in apertura del volume: «Tu te souviendras, hein», annuncia il tono dell'intera opera. Dal funerale di Victor Hugo al lettore, si stabilisce un'ininterrotta catena memoriale che mima in parte i processi della tradizione orale: narrazione frammentaria, punto di vista personale di un personaggio minore (in questo caso anche anagraficamente), incursione di elementi autobiografici, 
parallelo fra vicende storiche e microstoria famigliare, particolari vividissimi e minuziosamente descritti alternati a lacune e zone d'ombra della cronaca.

3 Un vai e vieni continuo fra le epoche, con l'aggiunta di testimonianze scritte ricercate dall'autore a conferma dei racconti della nonna, garantisce un certo equilibrio fra autenticità storica e accattivante immediatezza del racconto. Peccato che i riferimenti citati, articoli di giornale e altre testimonianze, siano integrati a una scrittura di tipo romanzesco e non rimandino a nessun elemento di bibliografia. In conclusione si potrà restare perplessi di fronte ad un'operazione che non sembra mirare chiaramente ad un particolare pubblico atteso, restando troppo impressionistica e narrativa per degli specialisti e forse troppo minuziosa per i semplici lettori curiosi. Sono tuttavia apprezzabili un'innegabile qualità di scrittura e le numerose e belle illustrazioni d'epoca (da «Le Monde illustré» del 6 giugno 1885) che arricchiscono il volume. 